Supporting Information

\title{
Synthesis of Ferrocene-modified Phenylazomethine Dendrimers Possessing Redox Switching
}

Mana Suzuki, Reina Nakajima, Masanori Tsuruta, Masayoshi Higuchi, Yasuaki Einaga, and Kimihisa Yamamoto*

Department of Chemistry, Faculty of Science and Technology, Keio University, Yokohama 223-8522, Japan

A Job plot of A

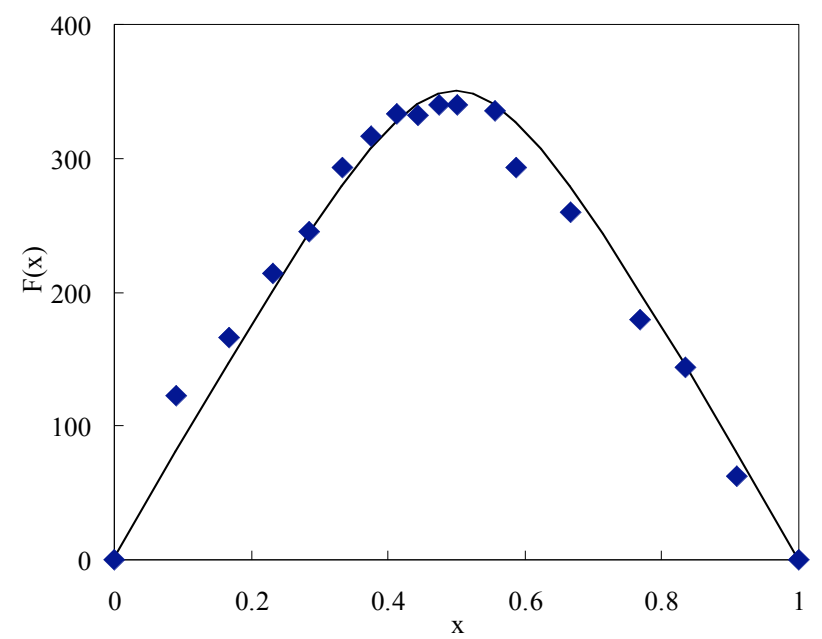

Figure S1. A Job plot of $\mathrm{SnCl}_{2}$ and end-ferrocene model compound ( $\mathrm{N}$-(ferrocenylmethylene) -2,6-dimethylbenzenamine). $\mathrm{F}(\mathrm{x})=$ Abs. $/\left(\mathrm{C}_{\text {model }}+\mathrm{C}_{\mathrm{SnCl} 2}\right)-\left(\varepsilon_{\text {model }}-\varepsilon_{\mathrm{SnCl} 2}\right) \mathrm{x}-\varepsilon_{\mathrm{SnCl} 2}, \mathrm{x}=\mathrm{C}_{\text {model }} /$ $\left(\mathrm{C}_{\text {model }}+\mathrm{C}_{\mathrm{SnCl} 2}\right)$; molar fraction of end-ferrocene model compound.. The solutions of equally concentrated $\mathrm{SnCl}_{2}$ and end-ferrocene model compound (M) (in chloroform/acetonitrile (1/1) solvent) were mixed in various proportions. The plot shows a maximum at a 0.5 mole fraction for the end-ferrocene model compound. This result indicates that the imine close to the ferroene forms a 1:1 complex with $\mathrm{SnCl}_{2}$. The equilibrium constant of complexation, $\mathrm{K}$, was determined to be ca. $10^{5}\left[\mathrm{M}^{-1}\right]$ by curve fitting a theoretical simulation to the experimental data. 
The diffusion coefficients

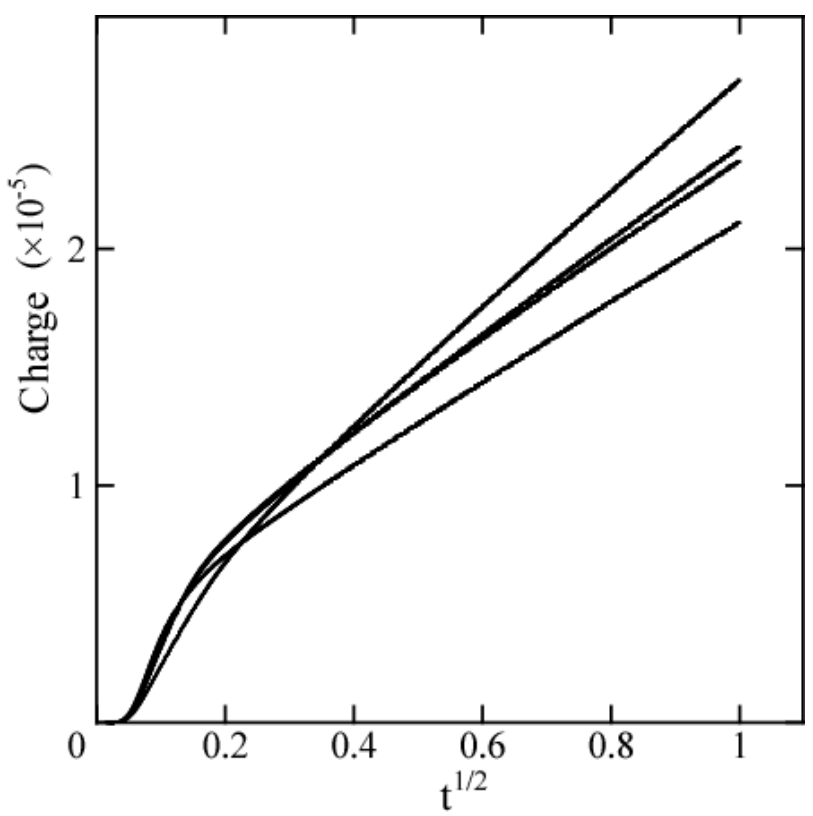

Figure S2. $t^{1 / 2}-\mathrm{Q}$ curve transformed from $\mathrm{t}-\mathrm{Q}$ curve by chronoamperometry experiments in $\mathrm{CNCH}_{3}$ $/ \mathrm{CHCl}_{3}=1 / 1$ under a nitrogen atmosphere.

$$
\begin{aligned}
& i(t)=i_{d}=\frac{n F D_{0}^{1 / 2} C_{0}^{*}}{\pi^{1 / 2} t^{1 / 2}} \\
& Q_{d}(t)=\int i d t=\frac{n F D_{0}^{1 / 2} C_{0}^{*}}{\partial^{1 / 2}} \int t^{-1 / 2} d t=\frac{2 n F D_{0}^{1 / 2} C_{0}^{*} t^{1 / 2}}{\pi^{1 / 2}}
\end{aligned}
$$

